Bull. Mater. Sci., Vol. 21, No. 3, June 1998, pp. 207-212. (C) Indian Academy of Sciences.

\title{
Thermally stimulated current and electrical conduction in metal (1)-ethyl cellulose-metal (1)/(2) systems
}

\author{
P K KHARE* ${ }^{*}$, ASHISH VERMA ${ }^{\dagger}$ and SUNIL K PALIWAL \\ Department of Postgraduate Studies and Research in Physics, Rani Durgavati Vishwavidyalaya, Jabalpur 482 001, \\ India \\ ${ }^{\dagger}$ Department of Physics, Dr H S Gaur University, Sagar 470001 , India \\ MS received 11 April 1997; revised 12 August 1997
}

\begin{abstract}
Depolarization current characteristics of solution grown pure ethyl cellulose (EC) films of about $20 \mu \mathrm{m}$ thickness have been studied as a function of electrode materials at constant poling field $\left(5 \times 10^{4} \mathrm{~V} / \mathrm{cm}\right)$ and poling temperature $40^{\circ} \mathrm{C}$. Thermally stimulated current (TSC) thermograms of EC consists of two well resolved peaks (located at $60^{\circ} \mathrm{C}$ and $140^{\circ} \mathrm{C}$ ) for $\mathrm{Al}-\mathrm{Al}$ system, which are attributed to the deorientation of strongly attached ethoxy groups of glycosidal units and diffusion of space charges either at electrodes or due to their thermal release at higher temperatures from the defect levels. For dissimilar electrode combinations $(\mathrm{Al}-\mathrm{Ag} / \mathrm{Cu} / \mathrm{Au} / \mathrm{Sn} / \mathrm{Pb})$, an indication of peak of lower magnitude at around $\left(50-70^{\circ} \mathrm{C}\right)$ alongwith a higher temperature peak $\left(140-155^{\circ} \mathrm{C}\right)$, have been observed. TSC parameters are found to change with the choice of electrode material. The dependence of dark current at $40^{\circ} \mathrm{C}$ in metal-ethyl cellulose-metal systems on applied voltage in the range $(2.0-5.0) \times 10^{4} \mathrm{~V} / \mathrm{cm}$ has also been studied. The results of current-voltage measurement on EC have been interpreted to show that the Schottky-Richardson mechanism is the controlling transport mechanism. Zero field current density extrapolated from $I-E^{1 / 2}$ plots are found to vary with metal work function.
\end{abstract}

Keywords. Thermally stimulated current; electrical conduction; ethyl cellulose; space charge relaxation; dipolar orientation; Schottky-Richardson mechanism.

\section{Introduction}

Thermally stimulated discharge (TSD) of polymers has become a widely used experimental technique for the investigation of various material parameters such as charge storage properties, determination of the mean depth of the internal charge, activation energies of traps and the trap structure of the material. The importance of carrier injection (Gutman and Lyons 1967; Koton 1968; Lampert and Mark 1970) for the explanation of electrical properties of organic solids has been long recognized. It is only in recent years that the possibility of technological application of electrification of polymers due to their contacts with metal has been discovered (Shrivastava et al 1981). The availability of new measuring techniques such as photocurrent (Wintle 1974) and thermally stimulated discharge (TSD) current (Turnhout 1975) has freshened interest in achieving a better understanding and application of the phenomena. Many studies and reviews (Pulfrey 1972; Kryozewski 1975; Khare and Srivastava 1992a, 1994; Khare et al 1994a) have been devoted to the problem of contacts and surface charge influence but there is controversy

*Author for correspondence about the causes of the polarity and amount of charge transferred under given conditions.

Ethyl cellulose (EC) is a thermally stable polymer that exhibits excellent chemical resistance and good mechanical properties and probably there is no report on contact electrification of EC using different metal contacts. Hence, it is worthwhile to investigate electret forming characteristics of EC in contact with metals providing a range of work functions. In view of this an analysis of the thermally stimulated current (TSC) and steady state current-voltage $(I-V)$ characteristics of $\mathrm{EC}$ polarized under identical conditions with a special reference to the nature of the electrode metals has been made to elucidate the electrode effect on injection in the polymer.

\section{Experimental}

The isothermal immersion technique was utilized for preparing thin films of ethyl cellulose (EC). The solution was prepared in a glass beaker by first dissolving $2.1 \mathrm{~g}$ EC in $30 \mathrm{ml}$ of chemically pure chloroform at room temperature and continuously stirred for $30 \mathrm{~min}$ by means of a teflon-coated magnetic stirrer. Thereafter, it was stirred and heated to $40^{\circ} \mathrm{C}$ to yield a homogeneous solution. The glass beaker containing the solution was 
then immersed in a constant temperature oil bath. Ultrasonically cleaned vacuum metallized microscopic glass slides were immersed vertically into the solution for a period of about $30 \mathrm{~min}$. After deposition of the film the glass slide was taken out and dried in an oven at $40^{\circ} \mathrm{C}$ for $24 \mathrm{~h}$. This was followed by room temperature outgassing at $10^{-5}$ torr for a further period of $24 \mathrm{~h}$. Aluminium, copper, silver, lead, tin and gold metals were vacuum deposited on the upper surface of the film to obtain a sandwich configuration. The following electrode combinations were used-Al-Al, $\mathrm{Al}-\mathrm{Ag}, \mathrm{Al}-\mathrm{Cu}, \mathrm{Al}-$ $\mathrm{Pb}, \mathrm{Al}-\mathrm{Sn}$ and $\mathrm{Al}-\mathrm{Au}$. The preparation of electrodes and measurement of thickness were the same as reported earlier (Khare and Srivastava 1992; Khare et al 1994b). The voltage was applied from a high voltage unit EC-4800 D and current was recorded with an electrometer (Keithley $600 \mathrm{~B}$ ), which was carefully shielded and grounded to avoid ground loops or extraneous electrical noise, at a linear heating rate of $4 \mathrm{~K} / \mathrm{min}$. The thickness of the sample was of the order of $20 \mu \mathrm{m}$ which was estimated by measuring the capacitance of the fabricated sandwiches taking the value of dielectric constant $\varepsilon$ of ethyl cellulose as 3 .

In the present case EC thermoelectrets were formed by a thermal method under identical polarizing conditions of temperature $\left(T_{\mathrm{p}}\right)$, higher field $\left(E_{\mathrm{p}}\right)$ and time $\left(t_{\mathrm{p}}\right)$, viz. $40^{\circ} \mathrm{C}, 5.0 \times 10^{4} \mathrm{~V} / \mathrm{cm}$ and $120 \mathrm{~min}$ but with different metal electrodes, namely copper, silver, lead, tin and gold, having different work functions. Thermoelectrets were shorted for $5 \mathrm{~min}$ to eliminate stray charges. The method of polarization of sample and measurement of TSC and steady current were same as reported earlier (Khare and Srivastava 1992; Khare et al 1993).

Below $40^{\circ} \mathrm{C}$ it was difficult to measure the small currents generated by voltage application in the measuring set up. The film was kept at $40^{\circ} \mathrm{C}$ for about $2 \mathrm{~h}$ and then a voltage was applied and the transient behaviour of the current was noted. Voltage application gave a current which was found to decrease to a much lower value in a matter of 2-5 min and then very slowly attain an almost steady value in a few hours. The same procedure was followed to observe the steady value of current at each step of voltage increment.

The depolarization kinetic data, activation energy $(E)$, charge released $(Q)$ and relaxation time $\left(\tau_{0}\right)$ for the observed peaks have been calculated using initial rise method of Garlick and Gibson (1948), Simson's rule and Bucci et al (1966) theory, respectively (table 1).

\section{Results and discussion}

Thermally simulated current (TSC) thermograms of ethyl cellulose (EC) samples formed by incorporating aluminium, copper, silver, lead, tin and gold as electrode metals with polarizing field, $E_{\mathrm{p}}=5.0 \times 10^{4} \mathrm{~V} / \mathrm{cm}$ at $T_{\mathrm{p}}=40^{\circ} \mathrm{C}$ are shown in figure 1 . In all the cases of electrode variation, an indication of peak at lower temperatures at around $50-70^{\circ} \mathrm{C}$ along with a broad TSC lying in between $140-155^{\circ} \mathrm{C}$ have been observed. For $\mathrm{Al}-\mathrm{Al}$ system, TSC thermograms are characterized with two peaks located at $60^{\circ}$ and $140^{\circ} \mathrm{C}$, respectively. Current-voltage $(I-V)$ characteristics of $\mathrm{EC}$ at $40^{\circ} \mathrm{C}$ with polarizing fields $(2.0-5.0) \times 10^{4} \mathrm{~V} / \mathrm{cm}$ using different metal electrodes in $I-E^{1 / 2}$ form are shown in figure 2 . It is clear from figures 1 and 2 that the current through the sample is greater when the upper electrode aluminium is replaced by silver, copper, tin, lead or gold.

The TSC thermograms are characterized by various peaks, due to dissipation of charges arising because of polarizations during charging process. The polarization of the material may arise due to various mechanisms, the important of which are dipole orientation, charge displacement, molecular and domain structures, macro/ microscopic displacement of ions with subsequent trapping, surface and space charge polarization etc. The trapping centres originate in the transition of the crystalline state into amorphous regions, in the rearrangement of molecules in the polymer chain and from the presence of impurities and defects in the materials. The various defects, in addition to giving rise to their own characteristic trapping levels, can also combine with other trapping centres present around them, and thus they can modify qualitatively as well as quantitatively the TSC spectra observed under polarizing conditions. $\mathrm{EC}$ is known to be a partial polar polymer. Its main chain is $\mathrm{C}-\mathrm{O}-\mathrm{C}$. The side groups also have a structure of the form $\mathrm{C}-\mathrm{O}-\mathrm{C}$ but they differ in electronegative nature from the main chain. The electronegativity of the main chain bond arises from the difference in the electronegativity of carbon and oxygen atoms; however, the electronegativity of the side groups arises from the difference in electronegativity of $\mathrm{H}_{2} \mathrm{C}-\mathrm{O}-\mathrm{C}_{2} \mathrm{H}_{5}$ and $\mathrm{C}-\mathrm{O}-\mathrm{C}_{2} \mathrm{H}_{5}$ bonds in the side chains. The slight polar nature of the polymer is due to the difference in electronegativity of the main chain and the side groups. The dipolar relaxation is maximum around the glass transition temperature $\left(T_{\mathrm{q}}\right)$. Its $T_{\mathrm{g}}$ lies in the temperature range $60-75^{\circ} \mathrm{C}$ for its atactio form and around $80^{\circ} \mathrm{C}$ for high molecular weight ethyl cellulose. In view of above characteristic of the polymer, it is expected to get first peak around $60-80^{\circ} \mathrm{C}$. This peak seems to be due to the orientation of strongly attached ethoxy groups of glycosidal units. The relaxation process has been found to be associated with an activation energy of $0.18 \mathrm{eV}$ and related to the segmental rotations or translations of the main chain (Khare et al 1996). It remains unaffected with heating rate and storage time (Khare and Srivastava 1993). The peak current is almost linearly dependent on poling field. It is suggestive of the dipolar polarization (Khare et al 1992). The second peak appears on the higher temperature side of the TSC thermograms. This peak may be considered due to space charge polarization arising out of localization of bulk 
generated and/or injected charge carriers in various available traps distributed energetically and spatially over the bulk of the sample. The joint motion/deorientation of the backbone chains of EC may be considered to contribute to some extent to this peak. The charge released from the trap levels at temperatures greater than $T_{\mathrm{g}}$ are very well documented previously (Dubey et al 1990; Khare et al 1992; Khare and Srivastava 1993). An indication of peak of smaller magnitude (around $50-70^{\circ} \mathrm{C}$ ) alongwith a broad TSC peak around $140-155^{\circ} \mathrm{C}$ have been found for dissimilar electrode combinations. These are space charge peaks modified by the type of metal (Shrivastava et al 1979), probably because the various metal-polymer interfaces possess different charge exchange rates, which change the space charge storage and current released by diffusion. The first stage of charging is carrier injection and the second stage is the entrapment of these charges in the border layer (Hino and Yamashita 1974). Consequently, the interpretation of depolarization appears to be reasonably possible in terms of charge detrapping of a space-charge build up due to carriers injected from the electrodes (Shatzkes
1978). At high fields, the charges are injected from the electrodes into the polymer film and then trapped. It is only at temperatures above the glass transition of EC that the molecular chains are sufficiently agitated to release the charge stored in them (Khare et al 1994c). The amount and sign of charge injected depends on the relative work function of the metal-polymer interface, i.e. the difference in energy between the Fermi level in metal and the bottom of the conduction band in the insulator. Therefore, the TSC parameters are changed when the electrode forming material is changed. It also seems possible that the dipolar peak either gets masked by the space charge peak or its contribution to the total polarization is very small (Khare et al 1994a).

The absence of peak at $60^{\circ} \mathrm{C}$ in $\mathrm{Al}-\mathrm{Sn}$ and $\mathrm{Al}-\mathrm{Pb}$ combinations may be due to oxidation of $\mathrm{Pb}$ and $\mathrm{Sn}$ metal electrodes. The ethoxy group being weakly electronegative and the oxide layer electropositive, will neutralize each other's effects to some extent. It is probably for this reason that in these two particular electrode combinations, the peak at $60^{\circ} \mathrm{C}$ is suppressed and only small humps are observed.

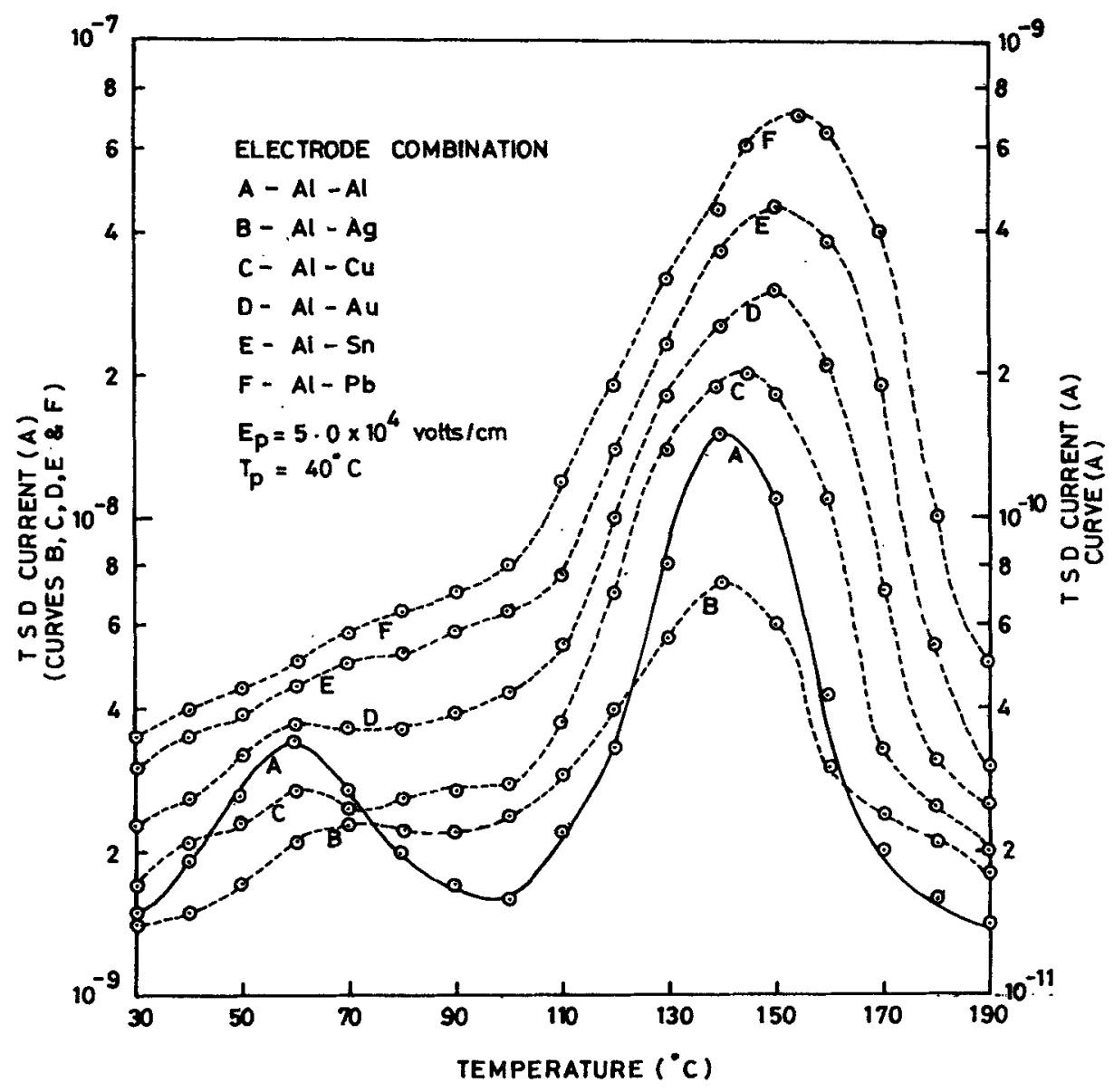

Figure 1. Effect of electrode materials on thermally stimulated current for ethyl cellulose samples with polarizing field $E_{\mathrm{p}}=5.0 \times 10^{4} \mathrm{~V} / \mathrm{cm}$ at polarizing temperature $T_{\mathrm{p}}=40^{\circ} \mathrm{C}$. 
In wide gap insulators and polymers with $n$-electrons, intrinsic carrier generation is not possible. Charge transfer from the metal depends on the electron levels in which the carriers shift freely under the influence of the applied field. The energy on this level may be given by (Baessler 1972)

$$
E_{\mathrm{b}}=E_{\mathrm{g}}=\left(I_{\mathrm{g}}-p^{+}\right)-\left(A_{\mathrm{c}}+p^{-}\right)=I_{\mathrm{c}}-A_{\mathrm{c}},
$$

where $I_{\mathrm{g}}$ is the ionization energy, $A_{\mathrm{c}}$ the electron affinity, $p^{+}$and $p^{-}$are the polarization energies and $I_{\mathrm{c}}$ the ionization energy of a molecule of the dielectric. The observed relation between the current and voltage points to a conduction mechanism in which the charge carriers are released by thermal activation over a coulombic potential barrier that is decreased by the electric field. The potential barrier can be one of the two types; (i) barrier between electrodes and dielectric taking the classic image force into consideration (Schottky emission), and (ii) barriers due to trapping centres in the dielectric (Poole-Frenkel effect). Taylor and Lewis (1971) assumed a more generalized form of the potential barrier rather than a Coulombic barrier usually employed in treatment of the RS effect.
They concluded that the potential barrier chosen is referred to the cathode-dielectric interface and probably is determined by a space-charge layer in the dielectric. Such space-charge layers are charged up by the absorption current. In the present case, $I-E^{1 / 2}$ plots may be interpreted in terms of Richardson-Schottky (RS) field assisted thermionic injection of carriers from metal electrodes.

The primary source of charge carriers is the electrode contacts. Carriers are generated in the bulk on account of thermal ionization of impurities and absorbed water molecules. Nath and Kumar (1980) have shown injection of holes in cellulose acetate film. Hole injection results in depletion of layer of negative charges creating a field at the interface between the electrode and film surface. When two metals are brought in close contact, a potential difference of work function $\phi_{2}-\phi_{1}$, is created between the two metals. The semi-insulating polymer differs from a metal, however, in that an electric field may exist within the interior of the semi insulator. For this reason the contact potential drop between the metal and the semi-insulator may take place within the material rather than at the contact interfaces. Along with the field, there may exist a depletion in the accumulation of charges in

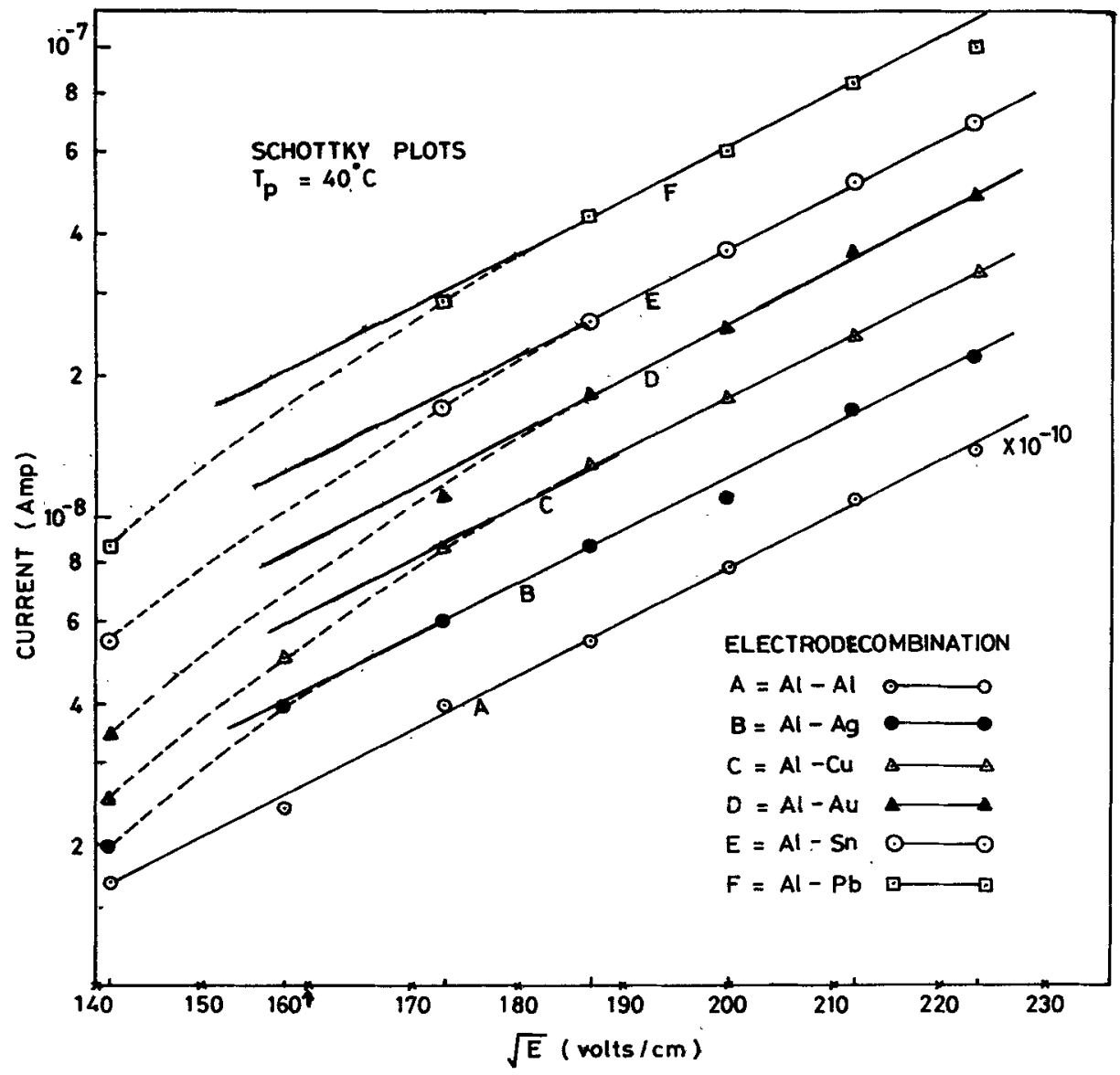

Figure 2. Log $I$ vs $\sqrt{E}$ plots (Schottky plots-similar and dissimilar electrode system). 
the surface layers (Khare and Srivastava 1992b). The work function of the metals used for contacts is lower compared to that of the work function of the polymeric material which creates an accumulation layer at the interfaces and leaves charged donors in the bulk. This in turn creates fields at the interfaces of the metal-polymer system (Khare et al 1994d). Suppose an insulator has a large energy gap with its Fermi level located above the mid gap and there is no surface state, then after contact with a metal surface, the electron transfer at contact equalizes both Fermi levels. The barrier height depends on the relative values of metal work function and the electron affinity of the insulator (Takai et al 1975). The surface state (Wintle 1977) is one of the factors which affects injection phenomena. Donor-like surface states located between the conduction band and Fermi level, after contact tend to bend the band edge towards the Fermi level, making electron injection from the metal much easier. On the other hand, acceptor like surface states located between the valence band and Fermi level act as a stepping-stone for electrons injected from the valence band of the insulator to the metal, thus, enhancing hole injection (Shrivastava et al 1979). Electrons must overcome the potential barrier $(x)$ given by

$$
x^{-}=\phi-A_{i},
$$

while holes are given by

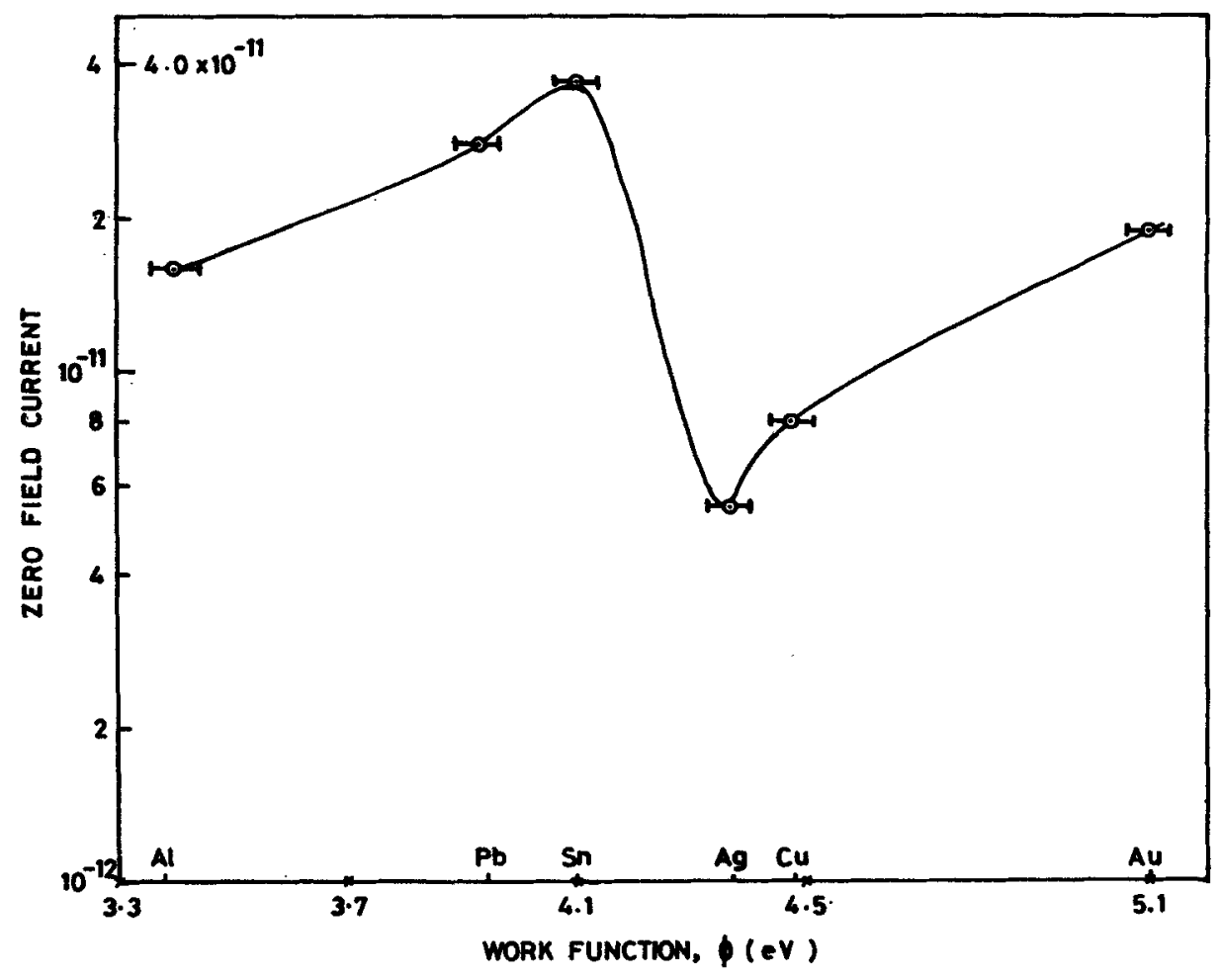

Figure 3. Zero field current vs metal work function for EC films.

Table 1. Depolarization kinetic data of electrode variation in ethyl cellulose films $\left(E_{\mathrm{p}}=5.0 \times 10^{4}\right.$ volts $\left./ \mathrm{cm}, T_{\mathrm{p}}=40^{\circ} \mathrm{C}\right)$.

\begin{tabular}{lccccc}
\hline $\begin{array}{l}\text { Electrode } \\
\text { combination }\end{array}$ & $\begin{array}{c}\text { Peak } \\
\text { temperature } \\
\left({ }^{\circ} \mathrm{C}\right)\end{array}$ & $\begin{array}{c}\text { Peak } \\
\text { current } \\
(A)\end{array}$ & $\begin{array}{c}\text { Activation } \\
\text { energy } \\
(\mathrm{eV})\end{array}$ & $\begin{array}{c}\text { Relaxation } \\
\text { time } \tau_{0} \\
(\mathrm{sec})\end{array}$ & $\begin{array}{c}\text { Charge } \\
\text { released } Q \\
\text { (Coul) }\end{array}$ \\
\hline $\mathrm{Al}-\mathrm{Al}$ & 60 & $3.2 \times 10^{-11}$ & 0.18 & $4.789 \times 10^{-11}$ & $6.222 \times 10^{-11}$ \\
& 140 & $1.5 \times 10^{-10}$ & 0.32 & $8.698 \times 10^{-10}$ & $1.576 \times 10^{-10}$ \\
$\mathrm{Al}-\mathrm{Ag}$ & 140 & $7.2 \times 10^{-9}$ & 0.48 & $9.978 \times 10^{-10}$ & $3.321 \times 10^{-9}$ \\
$\mathrm{Al}-\mathrm{Cu}$ & 145 & $2.0 \times 10^{-8}$ & 0.52 & $3.957 \times 10^{-9}$ & $2.234 \times 10^{-8}$ \\
$\mathrm{Al}-\mathrm{Au}$ & 150 & $3.0 \times 10^{-8}$ & 0.56 & $6.998 \times 10^{-9}$ & $8.768 \times 10^{-8}$ \\
$\mathrm{Al}-\mathrm{Sn}$ & 150 & $4.4 \times 10^{-8}$ & 0.59 & $7.345 \times 10^{-9}$ & $7.764 \times 10^{-7}$ \\
$\mathrm{Al}-\mathrm{Pb}$ & 155 & $7.0 \times 10^{-8}$ & 0.62 & $8.372 \times 10^{-9}$ & $9.957 \times 10^{-7}$ \\
\hline
\end{tabular}




$$
x^{+}=I_{c}-\phi,
$$

where $\phi$ is the metal work function, $A_{c}$ the electron affinity and $I_{\mathrm{c}}$ the ionization energy of a molecule of the dielectric.

In the present case the magnitude of TSC and steady state current was found to be higher in dissimilar electrode than similar electrode combinations. This shows the effect of materials of electrodes on the current of the sample sandwiched between them. The observations are consistent with the proposed R-S mechanism in which the carriers are injected over the field-dependent polymer-electrode interfacial barrier. The emission current is described by Richardson's equation

$$
J_{0}=A T^{2} \exp \left(-\frac{x}{k T}\right),
$$

where $J_{0}$ is the current density, $T$ the absolute temperature, $k$ the Boltzmann's constant and $A$ a constant.

The classical RS effect predicts a current-voltage relationship of the form

$$
J=A T^{2} \exp \left(-\frac{x}{k T}\right) \exp \left(\beta_{\mathrm{s}} V^{1 / 2}\right),
$$

with

$$
\beta_{\mathrm{s}}=\frac{e}{k T}\left(\frac{e}{4 \pi \varepsilon \varepsilon_{0} d}\right)^{1 / 2},
$$

where $d$ is the film thickness, $\varepsilon$ the dielectric constant, $\varepsilon_{0}$ the permittivity of the free space and $e$ the electronic charge. For zero field, (4) reduces to (3) and the current density depends on the potential barrier at a constant temperature. The zero-field current density $\left(J_{0}\right)$ was extrapolated by extending the linear portion of the $I-E^{1 / 2}$ plot backwards to meet the current axis. The values of $J_{0}$ vs metal work function have been plotted in figure 3 . The negative slope of the line when EC makes contact with $\mathrm{Ag}$ which signifies that the electron injection decreases for $\mathrm{Al}-\mathrm{Ag}$ electrode combination and so the zero field current decreases. The possible meaning that may be attached to the positively sloped line which is obtained when ethyl cellulose will be in contact with copper, tin, lead and gold is that, hole injection into the polymer film increases with the increase in metal function (Khare 1994) and hence zero field current also increases.

\section{Conclusion}

Thermally stimulated current and conduction current of ethyl cellulose films reveal a strong dependence on the electrode forming material which is the source of charge carriers responsible for conduction and observed polarization of the polymer.

\section{Acknowledgement}

The significant help provided by Mr Arun Kumar Khare, LIG-5, Shakun Sadan, New Anand Nagar, Adhartal, Jabalpur, is gratefully acknowledged.

\section{References}

Baessler H 1972 Kunststoffe 62115

Bucci C, Fieschi R and Guidi G 1966 Phys. Rev. 148816

Dubey V, Khare P and Saraf K K 1990 Indian J. Pure \& Appl. Phys. 28579

Garlick G F J and Gibson A P 1948 Proc. Phys. Soc. 60574

Gutman F and Lyons L E 1967 Organic semiconductors (New York: Wiley)

Hino T and Yamashita K 1974 Jpn J. Appl. Phys. 131015

Khare P K 1994 Indian J. Pure \& Appl. Phys. 32160

Khare P K and Srivastava A P 1992a Indian J. Pure \& Appl. Phys. 30 102, 131

Khare P K and Srivastava A P 1992b Thin Solid Films 208 233

Khare P K and Srivastava A P 1993 Indian J. Pure \& Appl. Phys. 31126

Khare P K, Surinder P and Srivastava A P 1992 Indian J. Pure \& Appl. Phys. 30165

Khare P K, Gaur M S, Alka Bajpai, Pandey R K and Srivastava A P 1993 Indian J. Pure \& Appl. Phys. 31326

Khare P K, Vishwakarma H L and Srivastava A P 1994a Indian J. Phys. A68 571

Khare P K, Gaur M S and Srivastava A P 1994b Indian J. Pure \& Appl. Phys. 3214

Khare P K, Keller J M, Gaur M S, Ranjeet Singh and Datt S C 1994c Polym. Int. 35337

Khare P K, Chandok R S, Dubey Neeraj and Srivastava A P 1994d Polym. Int. 35153

Khare P K, Keller J M, Gaur M S, Ranjeet Singh and Datt S C 1996 Polym. Int. 39303

Koton J E 1968 Organic semiconducting polymers (New York: Marcel Dekker)

Kryozewski M 1975 J. Polym. Sci. Polym. Phys. 50359

Lampert M A and Mark P 1970 Current injection in solids (New York: Academic Press)

Nath R and Kumar A 1980 Phys. Status Solidi a61 301

Pulfrey D L 1972 J. Phys. D 5647

Shatzkes M 1978 J. Appl. Phys. 494868

Shrivastava S K, Ranade J D and Srivastava A P 1979 Jpn J. Appl. Phys. 182303

Shrivastava S K, Ranade J D and Srivastava A P 1981 Polymer 221645

Singh R, Datt S C, Keller J M, Khare P K and Chandok R S 1991 IEEE 563

Takai Y, Osawa T, Chikao K, Mizutani T and Ieda M 1975 Jpn J. Appl. Phys. 10473

Taylor D M and Lewis T J 1971 J. Phys. D: Appl. Phys. 4 1346

Van Turnhout J 1975 Thermally stimulated discharge of polymer electrets (Amsterdam: Elsevier)

Wintle H J 1974 J. Polym. Sci. Polym. Phys. 122135

Wintle H J 1977 IEEE Trans. Electr. Insul. EI-12 97 